\title{
NOVEL IN VITRO CO-CULTURE METHODOLOGY TO INVESTIGATE HETEROTYPIC CELL-CELL INTERACTIONS
}

\author{
Elena F. Burguera*, Malak Bitar ${ }^{1}$ and Arie Bruinink
}

MaTisMed, Materials-Biology Interactions Lab, EMPA, Lerchenfelstrasse 5, CH-9014 St. Gallen, Switzerland

${ }^{1}$ Technical Research \& Development, Novartis Pharma AG, 4056 Basel, Switzerland

\begin{abstract}
Cell-cell interactions are of crucial importance for the formation of tissues, homeostasis and regeneration processes as well as reactions on foreign bodies including implants. So far, however, the importance of heterotypic cell-cell interactions in the in vitro evaluation of implant surfaces has been largely neglected. This work aims to develop an in vitro methodology that enables the in-depth investigation of heterotypic cell-cell interactions in a mixed co-culture system, and to validate it with a primary adult human bone-derived osteoblast cells (HBCs) - abdominal fibroblasts (HAFs) system. The methodology proposed combines a simple live labelling step, semiautomated fluorescence image acquisition and analysis to characterize the interactions between different cell types (cell population dynamics) in co-culture in terms of cell proliferation and cell spatial distribution of each cell type. In this co-culture system, direct cell-cell contacts between the two cell types were permitted while the determination of cell-type specific responses could still be elucidated. We could show that HAF proliferation was reduced in a way negatively correlated with the seeding $\mathrm{HBC} / \mathrm{HAF}$ ratio, i.e., a high proportion of $\mathrm{HBC}$ in the co-culture had an inhibitory effect on HAF proliferation. In all cultures segregation was found after 4 and 7 days of co-culture. HBCs were segregated at low ratios while HAFs were segregated at high ratios. Cellcell distances depended on the total cell number in the coculture but the dependence was different for each cell type.
\end{abstract}

Keywords: Biomaterial surfaces, 2D-co-culture, osteoblasts, cell proliferation, fibroblasts, in vitro.

\footnotetext{
*Address for correspondence (present address):

Elena F. Burguera

Osteoarticular and Aging Research Lab.

Biomedical Research Center - INIBIC

Complejo Hospitalario Universitario A Coruña 15006 A Coruña, Spain
}

Telephone Number: +34981178272

FAX Number: +34 981178273.

E-mail: elena.fernandez.burguera@sergas.es

\section{Introduction}

Currently, bone implant development approaches make use of in vitro tests to screen and identify promising new materials and devices before conducting in vivo experiments (Pearce et al., 2007; Pizzoferrato et al., 1994; Winn et al., 2006). These in vitro systems, for the most part, poorly represent the actual in vivo situation and they generally involve single cell type cultures (Cooper et al., 1998; Kirkpatrick et al., 2007). Yet, the integration of biomaterials in vivo depends on a complex interplay between numerous cell types that are attracted to the surface of the implant and that compete to contact it and colonize it (Anderson, 2001). This involves cellbiomaterial interactions (Puleo and Nanci, 1999), but also cell-cell interactions at the implant surface in which each of these cell types mutually affects the state of differentiation and functionality of the others, either by direct contact or indirectly through released factors (Sanchez et al., 2005; Wang et al., 2007). In the case of bone implants, fibroblasts and cells of the osteoblastic lineage are two of the most important cell types involved. Surface colonisation by fibroblasts in permanent bone implants would lead to encapsulation and ultimately to implant failure, whereas the direct apposition of bone forming cells on the implant surface would lead to new bone formation and implant osteointegration (Brånemark et al., 1977). Therefore, the fibroblast-osteoblast interactions at the implant surface might play a defining role in its fate. Consequently, in vitro co-culture methods as closely related to the in vivo situation as possible would be of interest to biomaterial scientists to obtain a better understanding of the osteoblast-fibroblast interactions and how to steer them to favour correct implant integration (Kirkpatrick et al., 2006). Several co-culture systems have been proposed and are in use to investigate heterotypic cell-cell interactions in vitro that relate to bone regeneration (reviewed recently by $\mathrm{Lu}$ ( $\mathrm{Lu}$ and Wang, 2008)). Some of these co-culture methods have been used to investigate fibroblast-chondrocyte (Nevo et al., 1993), osteoblast-chondrocyte (Jiang et al., 2005; Sanchez et al., 2005; Spalazzi et al., 2003), chondrocyte-mesenchymal stem cell (Gerstenfeld et al., 2002), as well as osteoblastendothelial cell (Unger et al., 2007) interactions. Osteoblast-fibroblast interactions were investigated by Wang et al. (Wang et al., 2007) and by Spalazzi et al. (Spalazzi et al., 2006) to elucidate their role in the reconstruction of the ligament-to-bone interface in anterior cruciate ligament. Their studies used either segregated cultures or mixed cultures in which the proliferative and/ or phenotypic behaviour of the cells in co-culture was found to differ from that of single cell type cultures, but 
the specific contributions of each cell type to these effects was not quantified.

In the present work, our aim was to develop an in vitro, semiautomated microscopy-based methodology to investigate heterotypic cell-cell interactions in a mixed coculture. We focused on the osteoblast-fibroblast interactions as a validation system due to their relevance to bone implant materials and, as a first step to develop and test the methodology, we used tissue culture plastic as substrate. However, the methodology should be applicable to other cell type combinations and future experiments will involve relevant biomaterial substrates like titanium. By making use of Vybrant ${ }^{\mathrm{TM}}$ DiI and Vybrant ${ }^{\mathrm{TM}}$ DiD vital labels and a simple labelling technique (Kaiser and Bruinink, 2004), direct cell-cell contacts between the two cell types were permitted while still enabling the monitoring of each cell type separately. These carbocyanine dyes were initially used for imaging neuronal cells in tissue preparations via retrograde labelling (Honig and Hume, 1986; Honig and Hume, 1989). Now they are widely used to label both neurons in tissues and cells in suspensions (Heinrich et al., 2007). Carbocyanine dyes are highly fluorescent in lipid bilayers, while they are essentially nonfluorescent or only weakly fluorescent in aqueous phase. Their spectral properties make this class of dyes ideal for staining the cytoplasmic membranes of the cells. The membrane staining is highly stable with very little dye transfer between cells. However, one disadvantage of these dyes is that the fluorescence intensity decreases roughly in parallel with the number of cell divisions, which limits the length of possible experiments (Ferrari et al., 2001).

Our objectives in the present work were: (1) to confirm that the developed methodology can be used to characterize cell-cell interactions in co-culture; (2) to prove that it can detect and quantify differences between the co-cultures and the single-cell type controls independently for each cell type; (3) to investigate the effect of the HBC/HAF seeding ratio on cell proliferation and segregation.

\section{Materials and Methods}

All chemicals and reagents were purchased from Sigma (Buchs, Switzerland) unless otherwise stated.

\section{Cells and cell culture}

Human primary bone cells. Primary human bone cells (HBCs) were outgrown from trabecular bone fragments obtained from four patients undergoing hip replacement surgery after informed consent (donors: $n \# 1$ : male, aged 75; n\#2: male, aged 61; n\#3: female, aged 59; n\# 4: female, aged 58). Briefly, the bone pieces were flushed with isolation medium to remove all blood cells and bone marrow as well as adipose tissue, until the bone pieces were white and clean. The obtained bone fragments were transferred to $75 \mathrm{~cm}^{2}$ culture flasks (Greiner Bio-One, Reinach, Switzerland) and incubated in proliferation medium ( $\alpha$-MEM (minimal essential medium) with $10 \%$ foetal calf serum (FCS), 1\% penicillin-streptomycin- neomycin antibiotic mixture (PSN) (All three from Invitrogen, Luzern, Switzerland) and $1 \mathrm{ng} / \mathrm{ml}$ basic fibroblast growth factor (FGF2.)). The bone-derived cells were allowed to grow over a period of 3 to 4 weeks or until preconfluent. Only primary cells of passage 1 were used for these experiments.

Human abdominal fibroblasts. Primary human abdominal fibroblasts (HAFs) were expanded in the laboratory from a biopsy of adult abdominal skin. HAFs were routinely cultured in Dulbecco's minimal essential medium (DMEM) supplemented with 10\% FCS and 1\% PSN. Passages 4 to 8 were used in the experiments.

Vital labelling. Both cell types were vitally labelled prior to seeding. HAF and HBC were labelled with Vybrant $^{\mathrm{TM}}$ DiD and Vybrant ${ }^{\mathrm{TM}}$ DiI, respectively (Molecular Probes, Luzern, Switzerland) following the procedure described by Kaiser and Bruinink (Kaiser and Bruinink, 2004). Briefly, both cell types were incubated for $15 \mathrm{~min}$ with $16 \mu \mathrm{l} / \mathrm{ml}$ of a $2.5 \mathrm{mg} / \mathrm{ml}$ stock solution of the corresponding dye followed by 2 washing steps. Absorption and fluorescence emission maxima are $644 \mathrm{~nm}$ and $665 \mathrm{~nm}$ for DiD and $549 \mathrm{~nm}$ and $565 \mathrm{~nm}$ for DiI, respectively. When used at the present concentrations these dyes did not affect cell proliferation, cell mass, viability or activity significantly (Honig and Hume, 1986; Kaiser and Bruinink, 2004). Upon cell division, daughter cells retain the fluorescent vital dye, but the fluorescence intensity decreases roughly in parallel with the number of cell divisions (Ferrari et al., 2001). DIC micrographs in combination with fluorescent images showed that all cells were labelled in the labelling procedure (not shown).

Co-culture experiments. We performed 4 independent experiments using for each one $\mathrm{HBCs}$ isolated from a different donor. In each experiment, the vitally labelled HAFs and HBCs were mixed and seeded with different $\mathrm{HBC} / \mathrm{HAF}$ ratios. All ratios were between 1 and 10, but varied from experiment to experiment (see Table 1). HBC and HAF seeding densities varied from 1250 to 5000 cells/ $\mathrm{ml}$ and from 250 to 2500 cells $/ \mathrm{ml}$, respectively, to obtain the target $\mathrm{HBC} / \mathrm{HAF}$ ratios. These seeding densities were selected in preliminary experiments to ensure that cocultures did not reach confluence in 7 days. Seeding densities, expected $\mathrm{HBC} / \mathrm{HAF}$ ratios and the experimentally measured ratios were included in Table 1. Co-cultures were identified with the donor number and a sequential number from 1 to 4 , for example, 2-1, refers to donor 2, co-culture 1, (see Table 1). Corresponding single cell type controls were also seeded under the same culture conditions. Controls had the same seeding densities as their specific cell types in the corresponding co-culture and were processed and analysed in the same way as the co-cultures. Co-cultures that showed significant differences in cell numbers at $24 \mathrm{~h}$ with their respective controls were discarded. Because of this, co-cultures 1-2 to 1-4 and 4-4 were not included in the calculations, (see below, Cell population dynamic analysis, proliferation by cell type). Each co-culture experiment was performed in triplicate in $35 \mathrm{~mm}$ Petri dishes (Greiner Bio-One, Reinach, Switzerland) with $2 \mathrm{ml}$ of $\alpha$-MEM supplemented with $10 \%$ FCS, 1\% PSN antibiotic mixture, $50 \mu \mathrm{M}$ ascorbic acid 
Table 1: Four independent coculture experiments were performed with HBCs from 4 different donors. Theoretical cell numbers per total scanned area were calculated from the seeding densities used and can be compared with the obtained experimental values. Experimental values at $24 \mathrm{~h}$ (day 1) were considered as the starting values. Abbreviations used: nHBC: number of HBCs; nHAF: number of HAFs; $\mathrm{N}$ : total number of cells, so that $\mathrm{N}=\mathrm{nHBC}+\mathrm{nHAF}$; R: ratio of HBCs to HAF, i.e. nHBC/nHAF. In addition, subscripts CC or CT refer to the coculture or the single cell type controls, respectively; and subscripts 1 or 7 refer to culture time. Data represent mean \pm standard deviation, $\mathrm{n}=3$.

\begin{tabular}{|c|c|c|c|c|c|c|c|c|}
\hline \multirow{3}{*}{ Coculture } & \multirow{2}{*}{\multicolumn{2}{|c|}{$\begin{array}{l}\text { Seeded } \\
\text { cells/ml }\end{array}$}} & \multicolumn{6}{|c|}{ Cell number per scanned area (per Petri dish) } \\
\hline & & & \multicolumn{2}{|c|}{ Theoretical } & \multicolumn{4}{|c|}{ Experimental } \\
\hline & HBC & HAF & $\mathrm{nHBC}_{\mathbf{C C}, 1}$ & nHAF $_{\mathbf{C C}, 1}$ & $\mathbf{N}_{\mathbf{C C}, 1}$ & nHBC $_{\mathbf{C C}, 1}$ & nHAF $_{\mathbf{C C}, 1}$ & $\mathbf{R}_{\mathbf{C C}, 1}$ \\
\hline 1-1 & 2500 & 500 & 300 & 60 & $410 \pm 56$ & $358 \pm 56$ & $52 \pm 6$ & $6.59 \pm 0.03$ \\
\hline $2-1$ & 2500 & 500 & 300 & 60 & $426 \pm 26$ & $343 \pm 25$ & $83 \pm 7$ & $4.15 \pm 0.04$ \\
\hline $2-2$ & 5000 & 1000 & 600 & 120 & $722 \pm 90$ & $565 \pm 85$ & $157 \pm 29$ & $3.61 \pm 0.17$ \\
\hline $2-3$ & 2500 & 1250 & 300 & 150 & $423 \pm 30$ & $278 \pm 30$ & $145 \pm 4$ & $1.92 \pm 0.23$ \\
\hline $2-4$ & 2500 & 500 & 300 & 60 & $421 \pm 48$ & $365 \pm 45$ & $55 \pm 17$ & $6.93 \pm 1.89$ \\
\hline $3-1$ & 2500 & 1250 & 300 & 150 & $423 \pm 29$ & $286 \pm 27$ & $137 \pm 9$ & $2.10 \pm 0.17$ \\
\hline $3-2$ & 5000 & 2500 & 600 & 300 & $824 \pm 84$ & $563 \pm 81$ & $261 \pm 24$ & $2.15 \pm 0.19$ \\
\hline $3-3$ & 2500 & 2500 & 300 & 300 & $575 \pm 42$ & $298 \pm 27$ & $277 \pm 31$ & $1.08 \pm 0.10$ \\
\hline $3-4$ & 2500 & 1250 & 300 & 150 & $489 \pm 27$ & $386 \pm 24$ & $103 \pm 12$ & $3.75 \pm 0.21$ \\
\hline 4-1 & 1250 & 250 & 150 & 30 & $187 \pm 24$ & $155 \pm 24$ & $32 \pm 4$ & $4.84 \pm 0.16$ \\
\hline $4-2$ & 2500 & 250 & 300 & 30 & $253 \pm 18$ & $228 \pm 17$ & $25 \pm 4$ & $9.33 \pm 0.82$ \\
\hline $4-3$ & 2500 & 250 & 300 & 30 & $242 \pm 26$ & $209 \pm 24$ & $33 \pm 11$ & $6.71 \pm 1.35$ \\
\hline
\end{tabular}

phosphate, $2 \mathrm{mM} \beta$-glycerophosphate and $10 \mathrm{nM} 1,25$ dihydroxyvitamine D3. This medium was selected in preliminary experiments that showed that alkaline phosphatase and osteocalcin expression was not upregulated in HAFs cultured in it as compared to HAFs cultured in DMEM with 10\% FCS, $1 \%$ PSN or downregulated in HBCs as compared to culture in full osteogenic medium (i.e., the current medium plus dexamethasone). Cultures were kept for 1, 4 or 7 days in humidified atmosphere with $5 \% \mathrm{CO}_{2}$ at $37^{\circ} \mathrm{C}$. After the specified culture time, cells were fixed with $2 \%$ paraformaldehyde with $0.3 \%$ Tween 20 and subsequently kept in phosphate buffer saline (PBS). Cell nuclei were stained with DAPI at $2 \mu \mathrm{g} / \mathrm{ml}$ after fixation.

\section{Co-culture characterization}

Cell population dynamics characterization relied on the analysis of data extracted from fluorescence micrographs from the co-cultures and the controls. Images were acquired and processed as follows (an outline of the methodology is included in Fig. 1a).

Semiautomatic image acquisition. For image acquisition we used a fluorescence microscope AxioImager
M1 with a 10x/0.3 EC Plan-neofluor objective, with a CCD camera AxioCam MRm (Zeiss, Göttingen, Germany). The microscope featured a motorized stage equipped with a Heidenhein linear sensor MT25 to compensate for lateral drifting and a motorized reflector revolver with the following filters: DAPI filter: excitation 335/383, dichroic beam splitter 395, emission filter 420-470; Cy5 filter: excitation $625 / 655$, dichroic beam splitter 660 , emission filter 655-750; and DsRed filter: excitation 538/562, dichroic beam splitter 570, emission filter 570/640, which allowed for semiautomatic image acquisition. Focus was acquired manually for one of the fluorescence channels and offsets for the rest of the channels were introduced in the automated program so that all fluorescence channels were in focus. For the controls only DAPI images were acquired. Four random images were taken from each Petri dish. Each image was a composition of 25 fields taken with the 10x objective and stitched together with Mosaix (AxioVision product suite, Zeiss, Göttingen, Germany) (Fig. 1b).

Automated image processing. CellProfiler (Web ref. 1) was used to analyze each fluorescence image (Carpenter et al., 2006). Specifically, a pipeline was designed to: (1) 
a

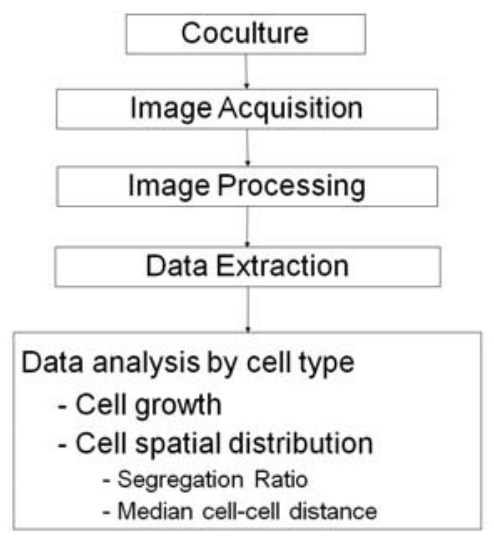

b

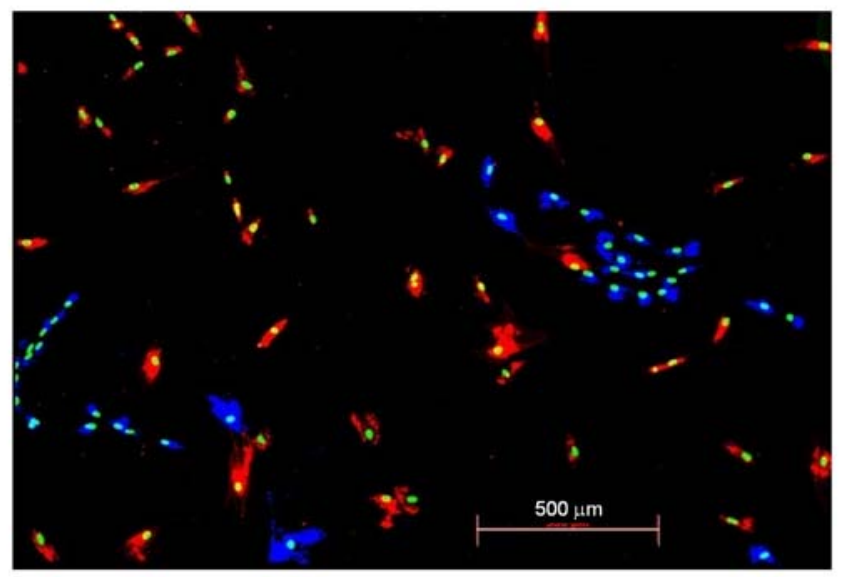

C

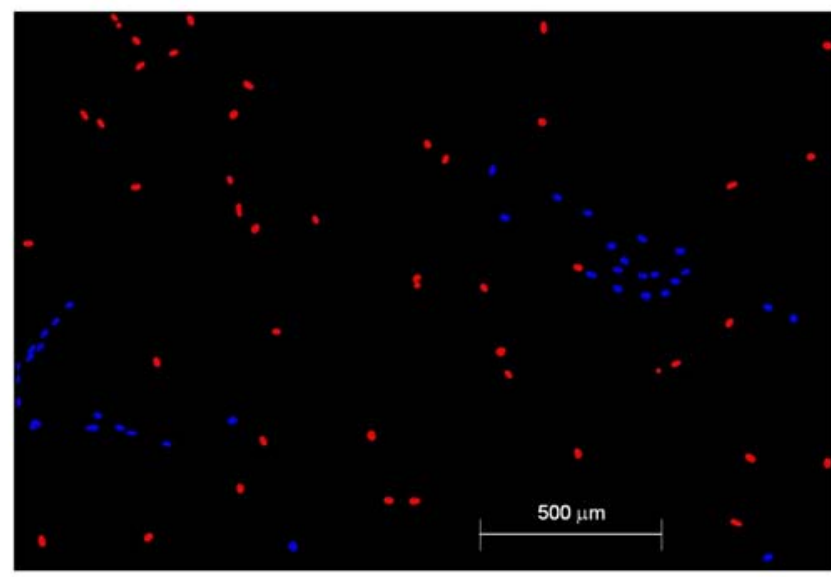

Fig. 1. (a) Outline of the developed methodology; (b) Example of a fluorescence microscopy image from one co-culture experiment (only about $30 \%$ of the image is shown to enhance detail). HBCs were labeled with DiI (red), HAFs were labeled with DiD (blue) and nuclei were labeled with DAPI (green). (c) Resulting image after CellProfiler processing. Red and blue nuclei identify HBCs and HAFs, respectively. identify the nuclei of all the cells in the image, (2) identify the cytoplasm of each cell and measure its colour intensity, (3) label in red the nuclei of cells with a red cytoplasm (HBCs) and label in blue the nuclei of cells with a blue cytoplasm (HAFs) and (4) return an image with only blue and red nuclei. In this manner the fluorescence images obtained from the co-cultures were transformed in nucleionly images where the colour of the nuclei was used to identify the original cell type (Fig. 1c). CellProfiler was installed in a HP workstation xw4600 with $8 \mathrm{~GB}$ of ram memory, solely dedicated to image processing. We used the high-resolution images generated by the microscope software $(\sim 6400 \times 4800$ pixels, 0.645 pixels $/ \mu \mathrm{m})$ without any size or resolution reduction. Images were adjusted for brightness and contrast to facilitate colour recognition by CellProfiler. Gamma settings were also adjusted when appropriate to aid the separation of adjacent nuclei, but this did not alter the content of the images. All the images were batch-processed using the same pipeline settings. The accuracy of image processing was validated by visually inspecting a random sample of images in one of the experiments (37 out of 288 or about $12 \%$ ) after the CellProfiler processing and manually counting the mistakes by comparing them to the original images. The resulting average error was $(1.01 \pm 0.52) \%$. This was considered an acceptable level of error that would not introduce any significant differences to the results.

Image analysis. We employed a custom-made Image Processing system (Visiometrics IPS 1.123, Visiometrics, Konstanz, Germany) to extract the relevant information from the nuclei-only images produced in the previous step. In each image, the software assigned a number to each cell and calculated their coordinates $(\mathrm{x}, \mathrm{y})$ in $\mu \mathrm{m}$ using the upper left corner as $(0,0)$ reference and the geometric centre 
of each nucleus as its position in the image. From the coordinates the program computed the distances between cells and it identified for each one, which cell was its closest neighbour (i.e., the one that was separated in the image by the shortest distance). The program also measured the colour intensity of each nucleus so that we could determine if the closest neighbour was of the same type or of a different type. The output information for each image was a database containing several parameters for each cell, namely its assigned number and coordinates, its colour and the assigned number of its closest neighbour. Data extraction was performed for each image and the databases were exported to Microsoft Excel for further processing.

\section{Cell population dynamics analysis}

We defined the parameters of interest described below to characterize the cell population dynamics in the cocultures. In all cases, we considered the experimental values obtained after $24 \mathrm{~h}$ (day 1) as the starting values (Table 1). We used the following abbreviations throughout the text: nHBC: number of HBCs; nHAF: number of HAFs; $\mathrm{N}$ : total number of cells, so that $\mathrm{N}=\mathrm{nHBC}+\mathrm{nHAF}$; R: ratio of $\mathrm{HBCs}$ to $\mathrm{HAF}$, i.e., $\mathrm{nHBC} / \mathrm{nHAF}$. In addition, subscripts CC or CT refer to the co-culture or the single cell type controls, respectively; and subscripts 1,4 or 7 refer to culture time, so that, for example, $\mathrm{R}_{\mathrm{CT}, 7}$ refers to the $\mathrm{HBC} / \mathrm{HAF}$ ratio resulting from dividing the number of $\mathrm{HBCs}$ in the HBC-only control by the number of HAFs in the HAF-only control after 7 days of culture.

\section{Cell proliferation by cell type}

Analysis of the databases obtained from the fluorescence images allowed us to monitor the changes in cell numbers (proliferation) in the co-cultures for each cell type (HBCs or HAFs) independently and to compare them to the changes in the single cell type controls, as a function of culture time or culture conditions. Two requirements were established for these comparison to be valid, namely i) that the number of cells by cell type in the co-culture and the number of cells in the respective controls were not significantly different at $24 \mathrm{~h}$ after seeding (i.e., that the number of $\mathrm{HBC}$ in the co-culture was not significantly different from the number of HBC in the HBC-only control at $24 \mathrm{~h}$ and likewise for the HAFs), and ii) that at $24 \mathrm{~h}$ after seeding the $\mathrm{HBC} / \mathrm{HAF}$ cell ratio in the co-culture $\left(\mathrm{R}_{\mathrm{CC}, 1}\right)$ was not significantly different from the ratio of the number of HBCs in HBC-only control divided by the number of HAFs in the HAF-only control $\left(\mathrm{R}_{\mathrm{CT}, 1}\right)$. We discarded 4 out 16 co-cultures from the 4 independent experiments that did not meet these requirements.

\section{Cell spatial distribution by cell type}

Culture segregation. Culture segregation might be observed when there is a tendency for any of the co-culture cell types to be preferentially surrounded by cells of the same type. Cells were homogeneously mixed and seeded randomly, therefore, any deviation from a random distribution after 4 or 7 days of co-culture, was assumed to indicate culture segregation, which can be a result of cell division and/or migration. We calculated the degree of culture segregation from the fluorescence images by comparing the experimental frequencies $\left(f_{\mathrm{E}}\right)$ of same type and different type pairs of closest neighbours with those theoretically obtained $\left(f_{\mathrm{T}}\right)$ for the same cell population with the same cell numbers and proportions, and assuming that it was homogeneously distributed over the same area. These calculations were performed as follows:

Experimental values. Experimental values were obtained by determining for each cell in the image the type (same or different) of its closest neighbour and calculating for the whole image the percentages of each combination of pairs, i.e., (percentage of HBCs that had another HBC as the closest neighbour and percentage that had a HAF as the closest neighbour, and likewise for the HAFs, for all the cells in the image). This yielded experimental values of the frequencies of same-type or different-type closest neighbour pairs for each image, $\left(f_{\mathrm{E}}\right)$.

Theoretical values. When the same population, with a total number of cells $\mathrm{N}$, composed of $\mathrm{nHBC}$ and $\mathrm{nHAF}$ cells is assumed to be randomly distributed across the same area, the theoretically expected frequency of pairs for the different possibilities of closest neighbour can be calculated with the equations below.

$$
\begin{array}{r}
{\left[f_{\mathrm{T}}\right]_{\mathrm{HBC}-\mathrm{HBC}}=\frac{\mathrm{nHBC} \cdot(\mathrm{nHBC}-1)}{\mathrm{N}(\mathrm{N}-1)} \cdot 100} \\
{\left[f_{\mathrm{T}}\right]_{\mathrm{HAF}-\mathrm{HAF}}=\frac{\mathrm{nHAF} \cdot(\mathrm{nHAF}-1)}{\mathrm{N}(\mathrm{N}-1)} \cdot 100} \\
{\left[f_{\mathrm{T}}\right]_{\mathrm{HBC}-\mathrm{HAF}}=\left[f_{\mathrm{T}}\right]_{\mathrm{HAF}-\mathrm{HBC}}=\frac{\mathrm{nHBC} \cdot \mathrm{nHAF}}{\mathrm{N}(\mathrm{N}-1)} \cdot 100}
\end{array}
$$

It follows that,

$$
\left[f_{\mathrm{T}}\right]_{\mathrm{HBC}-\mathrm{HBC}}+\left[f_{\mathrm{T}}\right]_{\mathrm{HAF}-\mathrm{HAF}}+\left[f_{\mathrm{T}}\right]_{\mathrm{HBC}-\mathrm{HAF}}+\left[f_{\mathrm{T}}\right]_{\mathrm{HBC}-\mathrm{HBC}}=100
$$

We defined a segregation ratio $(S)$ as the quotient of the experimental and theoretical frequencies for same-type pairs (i.e., $S=f_{\mathrm{E}} / f_{\mathrm{T}}$ ). Segregation ratios significantly higher than 1 were considered an indication of culture segregation.

Cell-cell distances. The distance between each cell and its closest neighbour was calculated from the cells coordinates for all the cells in each image. These cell-cell distances were computed to yield a median cell-cell distance by cell type (D). We compared same-type and different type cell-cell distances within the co-cultures to detect cell type dependent effects. Comparisons between co-cultures and controls were not possible due to differences in cell density.

\section{Statistical analysis}

Cell numbers for each cell type were calculated by adding the counted cells in the 4 scanned areas in each Petri dish and then averaging the values obtained for the 3 Petri dishes of the same experiment per condition. Values were expressed as average per total scanned area with one standard deviation. The same procedure was applied when calculating the frequencies of closest neighbours or cellcell distances, the data from the four scanned areas was pooled and the resulting values were averaged over the 3 Petri dishes of that experiment. Differences among groups were evaluated using one way ANOVA with post-hoc 
Table 2: Results from one-way ANOVA analysis of the data in figure 2 (values in the cocultures were compared to values in the controls for all the coculture experiments), $p<0.05$ was considered significant; (-) values in the coculture were significantly lower than those of the controls; (o) there was no statistically significant difference between the controls and the cocultures; $(+)$ values in the coculture were significantly higher than those of the controls. N: total cell number; nHBC: number of HBCs; nHAF: number of HAFs; R: nHBC/nHAF. Data were collected after 4 (D4) or 7 (D7) days of coculture.

\begin{tabular}{|c|c|c|c|c|c|c|c|c|}
\hline \multirow[t]{2}{*}{ Coculture } & \multicolumn{2}{|c|}{$\mathbf{N}$} & \multicolumn{2}{|c|}{ nHBC } & \multicolumn{2}{|c|}{ nHAF } & \multicolumn{2}{|c|}{$\mathbf{R}$} \\
\hline & D4 & D7 & D4 & D7 & D4 & D7 & D4 & D7 \\
\hline $1-1$ & $\mathrm{O}$ & - & $\mathrm{O}$ & $\mathrm{O}$ & - & $\mathrm{o}$ & $\mathrm{o}$ & + \\
\hline $2-1$ & $\mathrm{o}$ & - & o & - & - & $\mathrm{o}$ & $\mathrm{O}$ & $\mathrm{o}$ \\
\hline $2-2$ & $\mathrm{o}$ & - & $\mathrm{o}$ & - & - & $\mathrm{o}$ & $\mathrm{O}$ & $\mathrm{o}$ \\
\hline $2-3$ & o & - & o & - & $\mathrm{o}$ & $\mathrm{o}$ & o & $\mathrm{o}$ \\
\hline $2-4$ & - & - & $\mathrm{o}$ & - & - & - & + & + \\
\hline $3-1$ & o & o & o & $\mathrm{o}$ & $\mathrm{o}$ & $\mathrm{o}$ & o & $\mathrm{o}$ \\
\hline $3-2$ & o & o & o & $\mathrm{o}$ & $\mathrm{o}$ & $\mathrm{o}$ & $\mathrm{o}$ & $\mathrm{o}$ \\
\hline $3-3$ & o & o & o & - & $\mathrm{o}$ & $\mathrm{o}$ & $\mathrm{O}$ & - \\
\hline $3-4$ & - & - & - & - & - & - & $\mathrm{O}$ & $\mathrm{o}$ \\
\hline $4-1$ & - & - & $\mathrm{O}$ & - & - & - & $\mathrm{o}$ & $\mathrm{O}$ \\
\hline $4-2$ & - & - & $\mathrm{O}$ & $\mathrm{o}$ & - & - & + & + \\
\hline $4-3$ & $\mathrm{O}$ & - & $\mathrm{O}$ & $\mathrm{O}$ & - & $\mathrm{O}$ & $\mathrm{O}$ & + \\
\hline
\end{tabular}

analysis with Bonferroni correction. Correlations were tested using Pearson correlation analysis. In both cases, $p$-values of less than 0.05 were considered to be significant. Statistical analysis was performed with S-plus 2000.

\section{Results}

\section{Cell proliferation after 7 days in co-culture.}

In Fig. 2 the variations in cell numbers (nHBC and nHAF) in the co-cultures and the controls, together with the resulting $\mathrm{HBC} / \mathrm{HAF}$ ratios as a function of time, for all the individual experiments are presented. In all cultures (cocultures and controls) cell numbers of both cells types increased. In general, HBC/HAF ratios decreased progressively with time, in some instances even quite sharply. This was due to the differences in doubling times between HAFs, which doubled almost every $24 \mathrm{~h}$ and HBCs that had much longer doubling times and in addition showed donor-to-donor variations.

When comparing co-cultures to their controls after 7 days (see Table 2, recalling that each co-culture and its respective controls showed no significant differences at 24h), significant reductions in overall cell proliferation were seen in all co-cultures except 3-1, 3-2 and 3-3. In the later co-cultures no significant differences could be detected with the controls in overall cell proliferation. For the other co-cultures, the significant differences were the result of either a reduction in the HBC proliferation, HAF proliferation or both. HBC proliferation was reduced with respect to that of the respective controls in all co-cultures except 1-1, 3-1, 3-2, 4-2 and 4-3, whilst HAF proliferation was reduced in all co-cultures but 2-3, 3-1, 3-2 and 3-3.
Only co-cultures 3-1 and 3-2 showed no effect on either HBC or HAF proliferation as compared with their respective controls. We also evaluated the differences in the $\mathrm{HBC} / \mathrm{HAF}$ ratio $(\mathrm{R})$ between co-culture and controls, i.e., $\mathrm{R}_{\mathrm{CC}}$ compared to the ratio resulting from dividing the cell numbers in the respective single cell type controls, $\mathrm{R}_{\mathrm{CT}}\left(\mathrm{R}_{\mathrm{CT}}=\mathrm{nHBC}_{\mathrm{CT}} / \mathrm{nHAF}_{\mathrm{CT}}\right)$. We found significant differences in co-cultures 1-1, 2-4, 4-2, 4-3 and 3-3. In the later (co-culture 3-3), $\mathrm{R}_{\mathrm{CC}}$ was significantly lower than $\mathrm{R}_{\mathrm{CT}}$, while in the others (co-cultures 1-1, 2-4, 4-2, 4-3) $R_{C C}$ was significantly higher than $\mathrm{R}_{\mathrm{CT}}$. In the rest of the co-cultures there were no significant differences between $\mathrm{R}_{\mathrm{CC}}$ and $\mathrm{R}_{\mathrm{CT}}$. Some of these differences or tendencies pointing to these differences were already present after 4 days in co-culture (see Table 2).

\section{Effect of the starting $\mathrm{HBC} / \mathrm{HAF}$ ratio $\left(\mathrm{R}_{\mathrm{CC}, 1}\right)$ on cell proliferation}

To assess in how far the starting $\mathrm{HBC} / \mathrm{HAF}$ ratio influenced the differences described above we looked for correlations (Pearson correlation analysis) between the co-culture/ control ratios for the different co-culture parameters $(\mathrm{N}$, $\mathrm{nHAF}, \mathrm{nHBC}$ and $\mathrm{R})$ and the initial $\mathrm{HBC} / \mathrm{HAF}$ ratio $\left(\mathrm{R}_{\mathrm{CC}, 1}\right)$. This was plotted in Fig. 3(a-d), respectively. We found that, when the outcomes of all the experiments were combined in the same plot, the differences in overall cell proliferation between co-cultures and controls were correlated with the $\mathrm{R}_{\mathrm{CC}, 1}(\rho=-0.711, p<0.01)$ (Fig. 3a), higher starting ratios leading to more pronounced proliferation differences between controls and co-cultures. To determine cell type specific responses, the cell number variations for each cell type were plotted independently as a function of $R_{C C, 1}$. This is shown in Fig. $3 b$ for the 


\section{Coculture experiment}

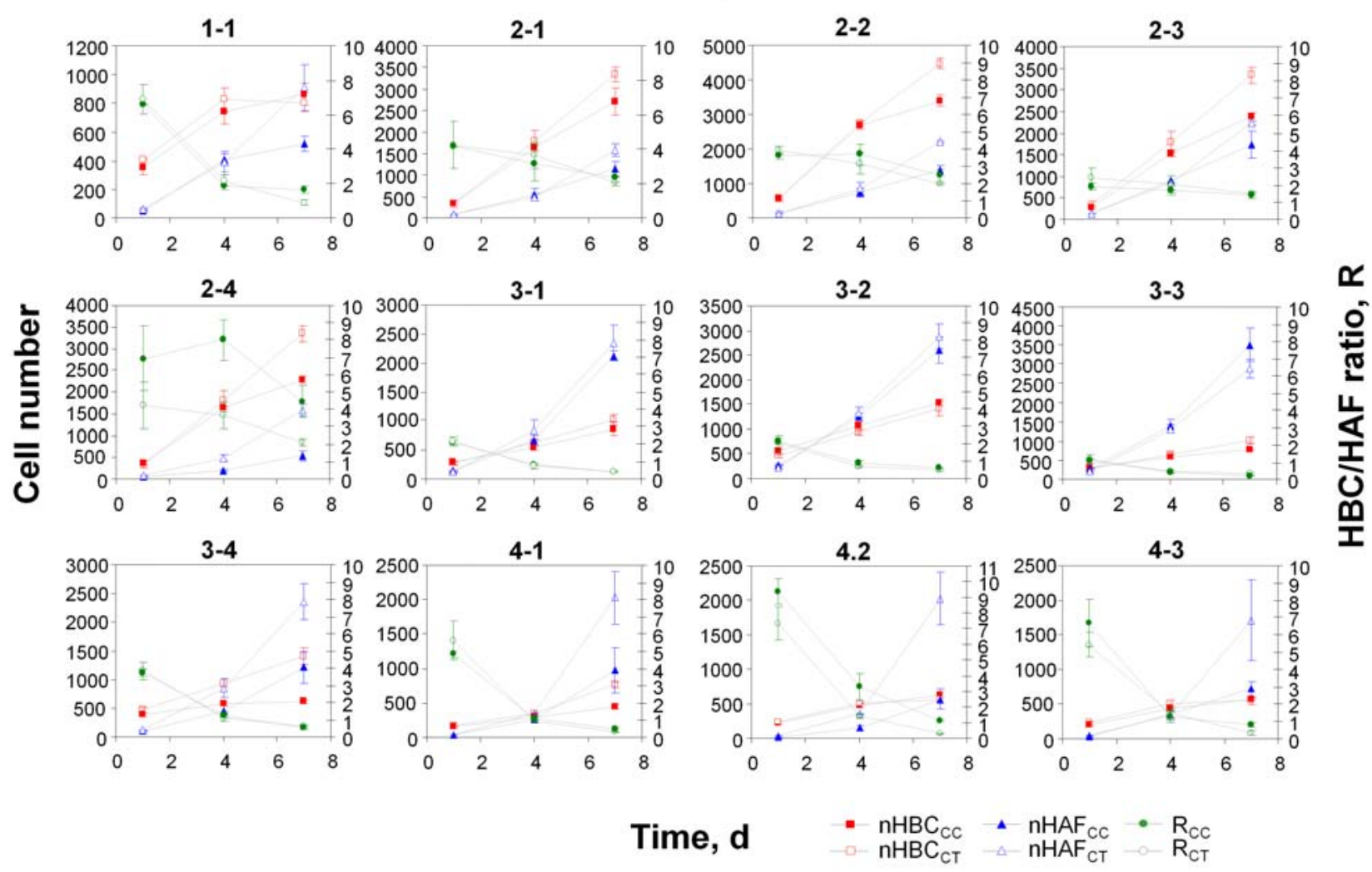

Fig. 2. Variations in cell numbers (nHBC and nHAF) in the co-culture and its corresponding controls, together with the resulting $\mathrm{R}_{\mathrm{CC}}$ and $\mathrm{R}_{\mathrm{CT}}$ as a function of time for all the individual co-culture experiments. Significant differences between co-cultures and controls at days 4 and 7 were included in table 2 for clarity. There were no significant differences between the co-cultures and their respective controls $24 \mathrm{~h}$ after seeding.

HAFs and in Fig. 3c for the HBCs. Pearson correlation analysis showed that $\mathrm{nHAF}_{\mathrm{CC}} / \mathrm{nHAF}_{\mathrm{CT}}$ (at day 7) was negatively correlated with $\mathrm{R}_{\mathrm{CC}, 1}(\rho=-0.886, p<0.01)$, in other words, the higher the starting $\mathrm{R}_{\mathrm{CC}, 1}$ the lower the proportion of HAF in the co-culture to HAF in the controls. In the case of the HBCs, there was a slight tendency in the opposite direction (most of the co-cultures that showed a significant reduction in $\mathrm{HBC}$ proliferation with respect to the controls were characterised by a low $\mathrm{R}_{\mathrm{CC}, 1}$ ) however, this was not significant $(\rho=0.363)$. As a result, the quotient of ratios in the co-culture and the controls at day $7\left(\mathrm{R}_{\mathrm{CC}, 7}\right)$ $\left.\mathrm{R}_{\mathrm{CT}, 7}\right)$ was also correlated with $\mathrm{R}_{\mathrm{CC}, 1},(\rho=0.904, p<0.01)$ (Fig. 3d); the highest starting $\mathrm{R}_{\mathrm{CC}, 1}(6.59$ and above) resulted in significantly higher $\mathrm{HBC} / \mathrm{HAF}$ ratios in the coculture than in the controls (i.e., $\mathrm{R}_{\mathrm{CC}, 7}>\mathrm{R}_{\mathrm{CT}, 7}$ ), whereas a starting ratio close to $1(1.08 \pm 0.10)$ led to a $R_{C C, 7}$ significantly lower than $\mathrm{R}_{\mathrm{CT}, 7}$. Intermediate starting ratios (i.e., $2<\mathrm{R}_{\mathrm{CC}, 1}<6$ ) resulted in no significant differences between co-culture and controls after 7 days.

\section{Effect of the total cell density on cell proliferation}

To ensure that the observed effects were not due to the increasing total cell density in the co-cultures we plotted the co-culture/control ratios for the different co-culture parameters $(\mathrm{N}, \mathrm{nHAF}, \mathrm{nHBC}$ and $\mathrm{R})$ as a function of the total cell density in the co-culture at day $7\left(\mathrm{~N}_{\mathrm{CC}, 7}\right)$ (Fig. 3e$h$, respectively). If there was a cell density effect we would expect the co-cultures that showed significant differences with their controls (marked with empty squares in the figures) to be concentrated in the lower right side in Fig. $3 \mathrm{e}-\mathrm{g}$ and in the upper right side in Fig. $3 \mathrm{~h}$. However, this was not the case (in fact there was, if at all, the opposite tendency, although it was not significant) and these cocultures seem to be randomly distributed over the whole range of cell densities and not concentrated in the right side of the figures corresponding to high densities. Therefore, cell proliferation inhibition in the co-culture was not the result of cell contact inhibition due to high cell densities in the co-culture.

\section{Variations in cell spatial distribution by cell type - Co-culture segregation}

Fig. 4 includes a plot of the experimental frequency $\left(f_{\mathrm{E}}\right)$ of same type closest neighbours versus the theoretical ones $\left(f_{\mathrm{T}}\right)$ for HBCs and HAFs at $24 \mathrm{~h}$. Experimental values showed a 1 to 1 correspondence with the theoretical values (One-way ANOVA, $p>0.05$ ), i.e., the random seeding led to a random distribution of both cell types at $24 \mathrm{~h}$, in all the experiments (there were two exceptions for HAFs in co-culture 2-2 and 2-3). For the later time points, we calculated the segregation ratios for HBCs and HAFs $\left(S_{\mathrm{HBC}}\right.$ and $S_{\mathrm{HAF}}$ ) as defined in the methods section. We found that $S$ ratios were strongly correlated with the $\mathrm{R}_{\mathrm{CC}}$ ratio at day $7\left(S_{\mathrm{HBC}}: \rho=-0.820, p<0.01 ; S_{\mathrm{HAF}}: \rho=0.966, p<0.01\right)$ and 


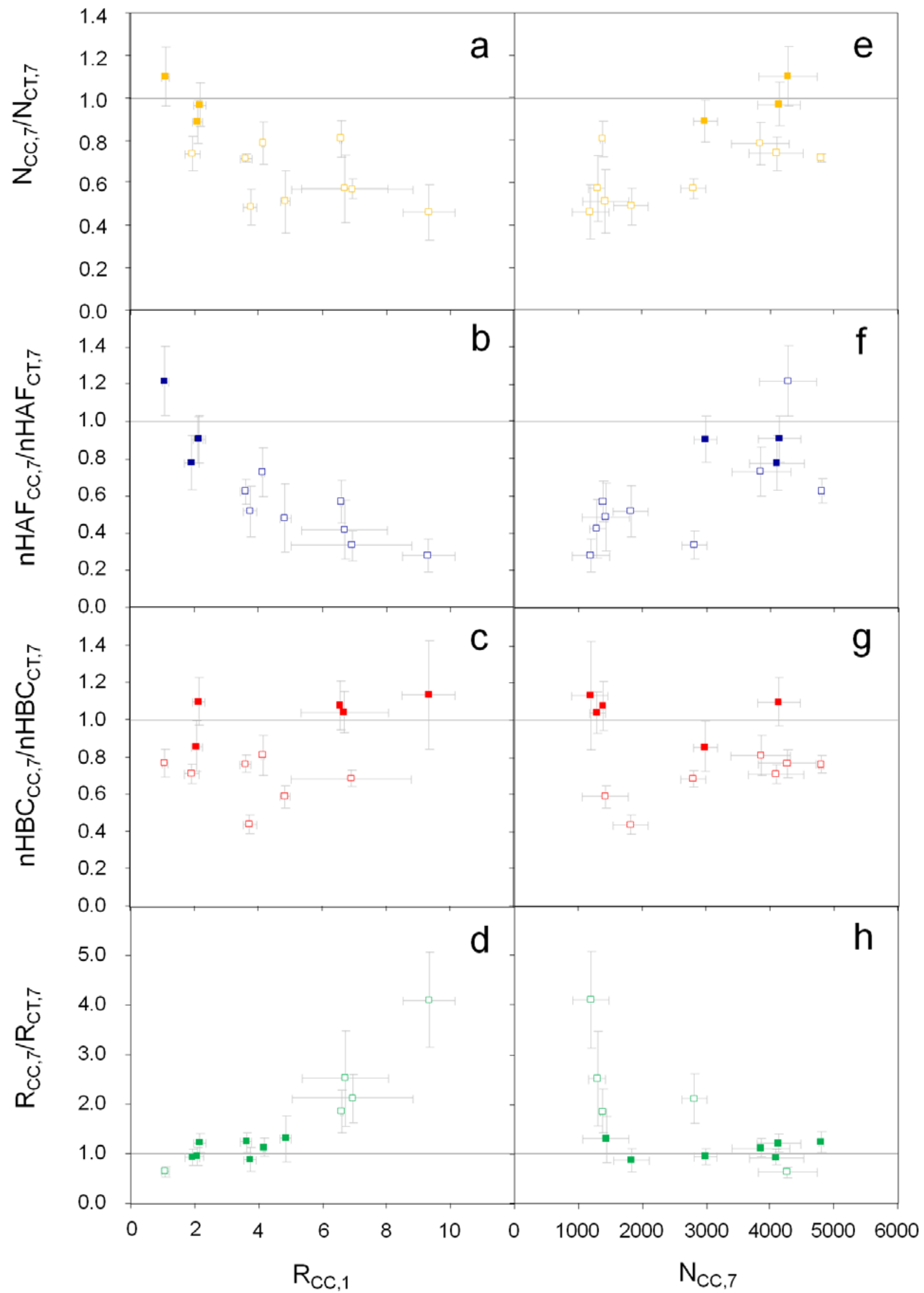

Fig. 3. Co-culture/control ratios at day 7 for the different culture parameters (N, nHAF, nHBC and R) as a function of the initial $\mathrm{nHBC} / \mathrm{nHAF}$ ratio $\left(\mathrm{R}_{\mathrm{CC}, 1}\right)(\mathbf{a}, \mathbf{b}, \mathbf{c}$ and $\mathbf{d}$, respectively), and as a function of the overall cell density in the co-cultures after 7 days in culture $\left(\mathrm{N}_{\mathrm{CC}, 7}\right)(\mathbf{e}, \mathbf{f}, \mathbf{g}$ and $\mathbf{h}$, respectively). Co-culture/control ratios significantly different than 1 were marked with empty squares (one-way ANOVA, $p<0.05$ ). 


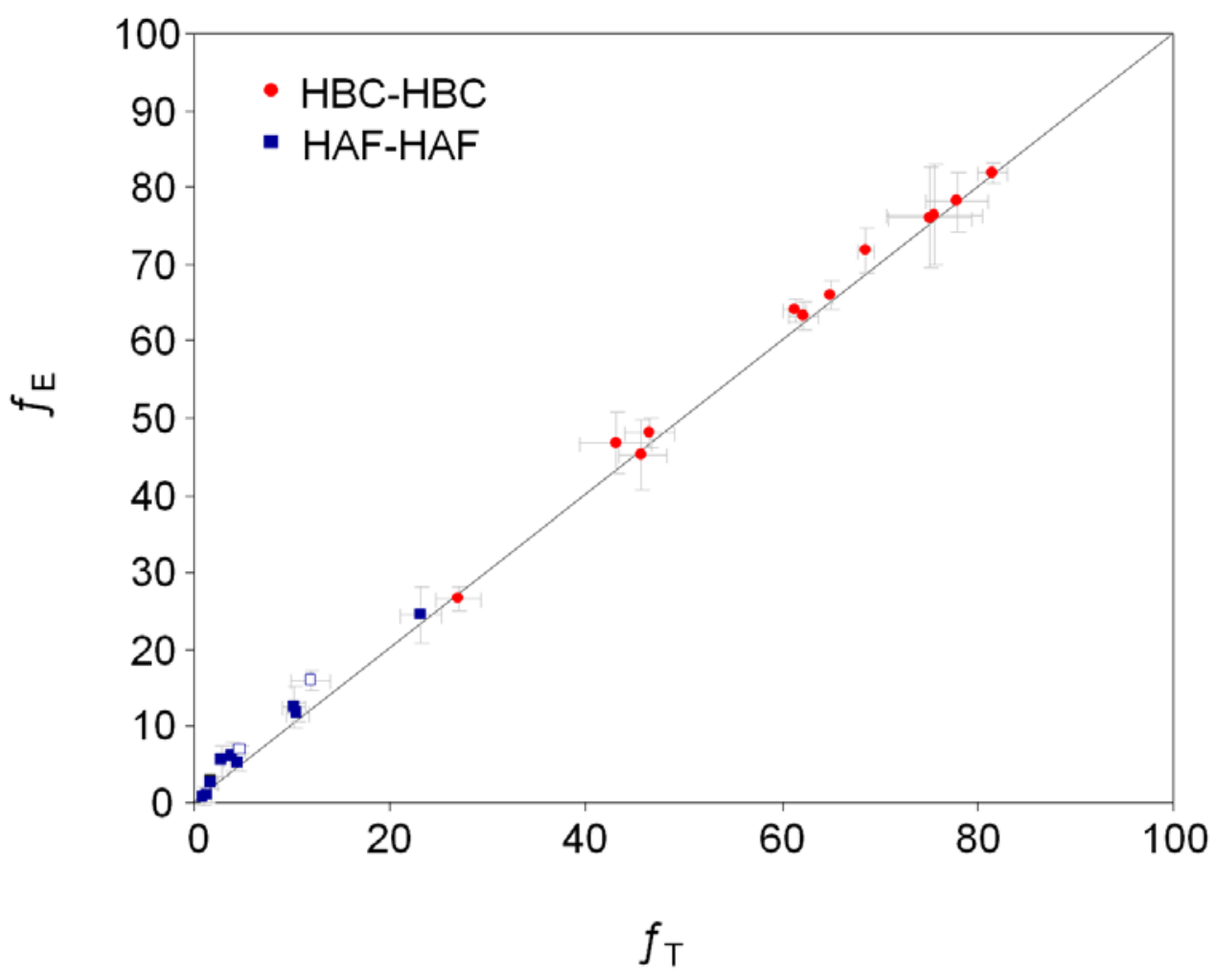

Fig. 4. Random seeding of the mixed cell population led to a random spatial distribution at $24 \mathrm{~h}$. Experimental frequencies of same type closest neighbor $\left(f_{\mathrm{E}}\right)$ showed a 1 to 1 correspondence with the ones theoretically calculated for an equivalent population homogenously distributed over the same area $\left(f_{\mathrm{T}}\right)$. Ratios different than 1 were marked with empty squares (one-way ANOVA, $p<0.05$ ).

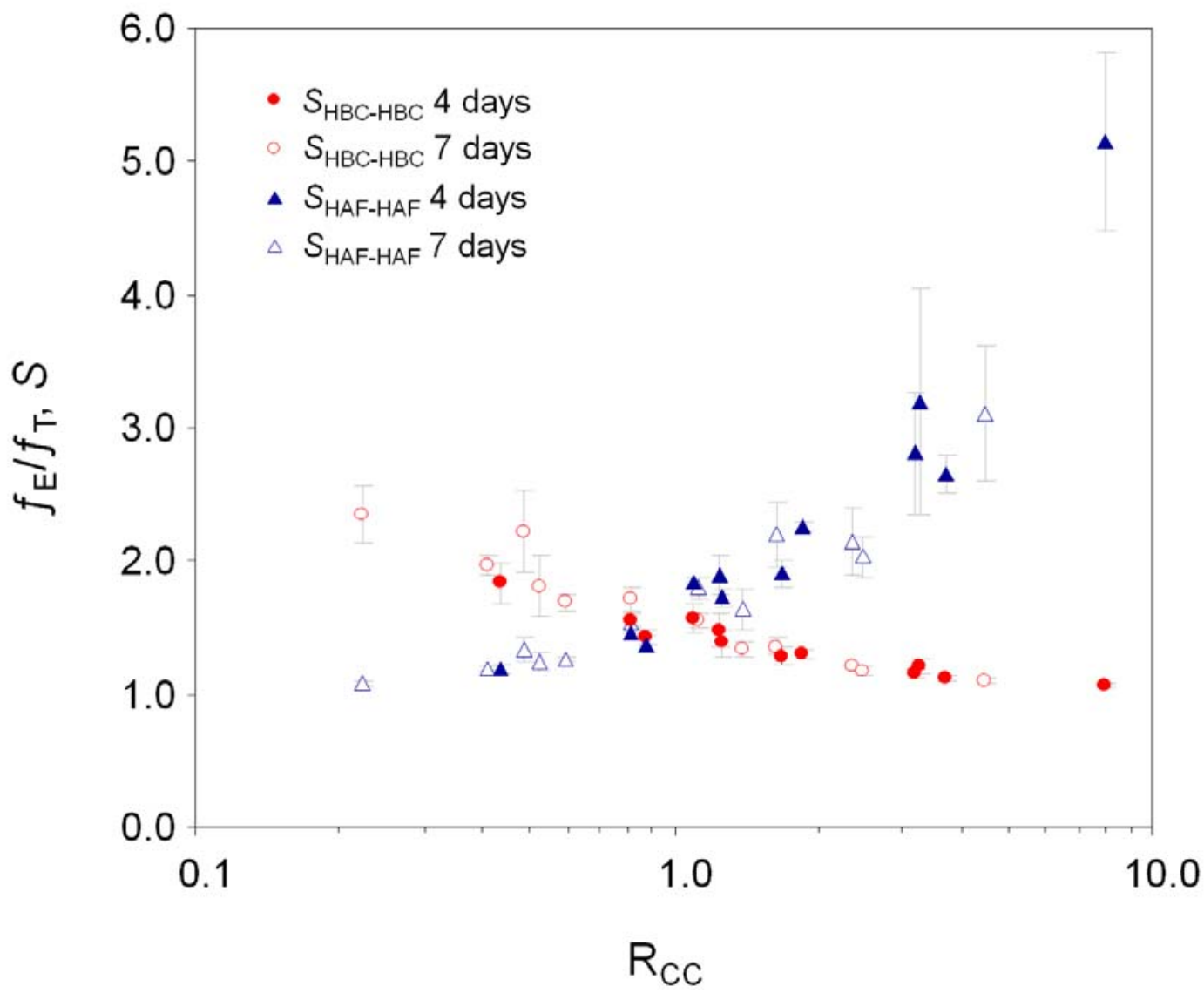

Fig. 5. Variations in segregation ratios $(S)$ for HBCs and HAFs as a function of the HBC/HAF ratio at days 4 and 7. 


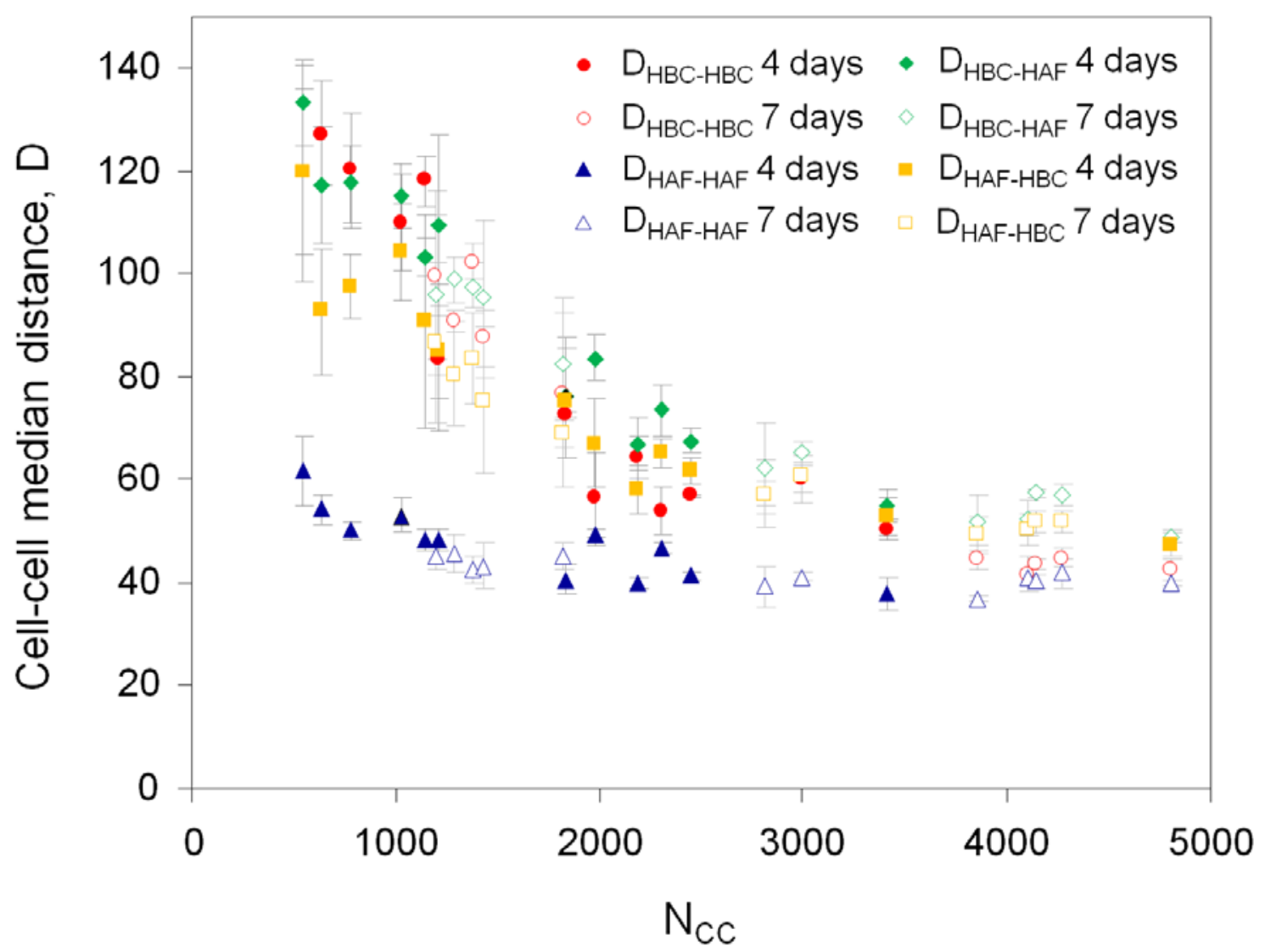

Fig. 6. Variations in the median same-type and different type cell-cell distances to the closest cell (D) as a function of the cell density in the co-cultures at days 4 and 7.

also at day $4\left(S_{\mathrm{HBC}}: \rho=-0.775, p<0.01 ; S_{\mathrm{HAF}}: \rho=0.982\right.$, $p<0.01$ ) (Fig. 5). HAFs were only not significantly segregated at ratios below 0.5 , and $\mathrm{HBCs}$ at ratios above 2.5. The result was that $\mathrm{HBCs}$ were significantly more segregated in co-cultures with low $\mathrm{R}_{\mathrm{CC}}$ and HAFs were segregated at high $\mathrm{R}_{\mathrm{CC}}$, i.e., each cell type was more segregated when they were the minority cell type. Nevertheless, even in cultures with a $R_{C C}$ of around 1 (culture 4-1 with $\mathrm{R}_{\mathrm{CC}}$ of $1.10 \pm 0.11$ at day 4 and culture 42 with $R_{C C}$ of $1.12 \pm 0.11$ at day 7 ), both cell types showed a significant degree of segregation, $1.57 \pm 0.11$ at day 4 and $1.56 \pm 0.06$ at day 7 respectively, for $\mathrm{HBCs}$, and $1.84 \pm 0.04$ at day 4 and $1.80 \pm 0.08$ at day 7 respectively, for HAFs. This means that even at a 1 to 1 ratio HBCs and HAFs were respectively 1.6 and 1.8 times more likely to be close to a cell of the same type than it would be expected from a random distribution.

\section{Variations in cell spatial distribution by cell type - Cell-cell distances}

In line with expectations, median cell-cell distances (to the closest neighbour) in the co-cultures were found to be strongly correlated with the total cell number $(\mathrm{N})$ at all time points (Pearson correlation analysis, $p<0.01$ ). However, this dependence was different for both cell types. As a result of random seeding, when comparing sametype (i.e., $\mathrm{D}_{\mathrm{HBC}-\mathrm{HBC}}$ to $\mathrm{D}_{\mathrm{HAF}-\mathrm{HAF}}$ ) or different-type (i.e., $\mathrm{D}_{\mathrm{HBC}-}$ HBC to $\mathrm{D}_{\mathrm{HBC}-\mathrm{HAF}}$, or $\mathrm{D}_{\mathrm{HAF}-\mathrm{HAF}}$ to $\mathrm{D}_{\mathrm{HAF}-\mathrm{HBC}}$ ) median distances at $24 \mathrm{~h}$, there were no significant differences in all but 3 co- cultures $\left(2-2,2-3\right.$ and 2-4) in which $\mathrm{D}_{\text {HAF-HAF }}$ was significantly lower than $\mathrm{D}_{\mathrm{HBC}-\mathrm{HBC}}$. Conversely, at days 4 and $7, \mathrm{D}_{\mathrm{HAF}-\mathrm{HAF}}$ was significantly lower than $\mathrm{D}_{\mathrm{HBC}-\mathrm{HBC}}$ in all but 2 co-cultures at day 4 (3-2 and 3-3) and 3 co-cultures at day 7 (2-2, 2-3 and 3-3). $\mathrm{D}_{\mathrm{HAF}-\mathrm{HAF}}$ was also significantly lower than $\mathrm{D}_{\mathrm{HBC}-\mathrm{HAF}}$ or $\mathrm{D}_{\mathrm{HAF}-\mathrm{HBC}}$ in all co-cultures at day 4 and day 7 (Fig. 6). Therefore, even though the median cell-cell distance (i.e., the median distance between any cell and its closest neighbour) was a function of the cell density, the characteristic cell-cell distance for a given cell density was significantly different for each cell type. Different starting $\mathrm{R}_{\mathrm{CC}}$ or starting cell densities $\left(\mathrm{N}_{1}\right)$ did not directly influence cell-cell distances as can be seen in the examples included in table 3 in which the obtained cellcell distances are compared for co-cultures with different $\mathrm{N}_{1}$ or $\mathrm{R}_{\mathrm{CC}, 1}$. Additionally, median distances were not correlated with the segregation ratios (HBCs $\rho=0.161$, $p>0.05$; HAFs $\rho=-0.446, p>0.05$ ), in other words, high $S$ values were not associated with reduced cell-cell distances, as it can be seen also in table 3 .

\section{Discussion}

Currently, it is well recognized that cell-cell interactions are an important determinant in how a biological environment reacts to materials and drugs. Cell-cell interactions occur via released signalling molecules and via direct contact between individual cells. Several 
Table 3: Different starting HBC/HAF ratios $\left(\mathrm{R}_{\mathrm{CC}, 1}\right)$ or cell densities $\left(\mathrm{N}_{\mathrm{CC}, 1}\right)$ did not directly influence cell-cell distances (D). For columns 2 to 5 values connected with a vertical line were not significantly different (One-way ANOVA on the values in the table only, $p>0.05$ ).

\begin{tabular}{|c|c|c|c|c|c|c|c|}
\hline Coculture & $\mathbf{N}_{\mathbf{C C}, 7}$ & $\mathbf{R}_{\mathrm{CC}, \mathbf{1}}$ & $\mathrm{N}_{\mathrm{CC}, \mathbf{1}}$ & $\mathbf{D}_{\mathrm{HBC}-\mathrm{HBC}, 7}$ & $\mathbf{D}_{\text {HAF-HAF }, 7}$ & $S_{\mathrm{HBC}}$ & $S_{\mathrm{HAF}}$ \\
\hline $1-1$ & $1385 \pm 91$ & $6.59 \pm 0.03$ & $410 \pm 56$ & $102 \pm 3$ & $42 \pm 3$ & $1.36 \pm 0.07$ & $2.20 \pm 0.24$ \\
\hline $4-1$ & $1427 \pm 326$ & $4.84 \pm 0.16$ & $187 \pm 24$ & $88 \pm 5$ & $43 \pm 4$ & $2.22 \pm 0.30$ & $1.34 \pm 0.09$ \\
\hline $4-3$ & $1295 \pm 117$ & $6.71 \pm 1.35$ & $242 \pm 26$ & $91 \pm 2$ & $46 \pm 4$ & $1.72 \pm 0.09$ & $1.54 \pm 0.08$ \\
\hline $4-2$ & $1193 \pm 205$ & $9.33 \pm 0.82$ & $253 \pm 18$ & $100 \pm 16$ & $45 \pm 3$ & $1.56 \pm 0.06$ & $1.80 \pm 0.08$ \\
\hline $2-1$ & $3854 \pm 366$ & $4.15 \pm 0.04$ & $426 \pm 26$ & $45 \pm 3$ & $37 \pm 1$ & $1.20 \pm 0.02$ & $2.15 \pm 0.26$ \\
\hline $2-3$ & $4101 \pm 341$ & $1.92 \pm 0.23$ & $423 \pm 30$ & $42 \pm 3$ & $41 \pm 2$ & $1.34 \pm 0.05$ & $1.64 \pm 0.15$ \\
\hline $3-2$ & $4140 \pm 281$ & $2.15 \pm 0.19$ & $824 \pm 84$ & $44 \pm 1$ & $40 \pm 1$ & $1.70 \pm 0.06$ & $1.27 \pm 0.02$ \\
\hline $3-3$ & $4277 \pm 446$ & $1.08 \pm 0.10$ & $575 \pm 42$ & $45 \pm 2$ & $42 \pm 3$ & $2.34 \pm 0.22$ & $1.09 \pm 0.01$ \\
\hline
\end{tabular}

successful co-culture methodologies to investigate heterotypic cell-cell interactions in mixed co-cultures can be found in the recent literature. However, these methodologies present some limitations that restrict their use and delimit the information that can be obtained with them. In developing our methodology we tried to overcome those limitations. For instance, Oberringer et al. (Oberringer et al., 2007; Oberringer et al., 2008) developed a wound healing model using a endothelial cells-fibroblastmyofibroblast co-culture in which cells were identified through the use of specific immunostaining, (endothelial cells were positive for von Willebrand factor, myofibroblasts for $\alpha$-smooth muscle actin and the remaining unstained cells were considered fibroblasts). Using this methodology they could elucidate cell-specific proliferation by manually counting the fluorescent cells, but the application of this method requires the availability of specific antibodies that show no cross reactivity between the relevant cell types. This methodology could not be applied to for instance, osteoblast-fibroblast co-cultures due to the absence of a specific staining for fibroblasts. Furthermore, the possibility that at the end of the experiment specific proteins are not synthesized due to an effect of the co-culture and/or transdifferentiation was not taken into account. In addition, manual counting is labour intensive and time consuming. A similar approach as described in the present study was used by Fuchs et al. (Fuchs et al., 2007) who investigated osteoblastendothelial cell interactions in co-culture. Both cell types were identifiable through the use of a combination of a fluorescent cell tracker and endothelial markers. However, this study focused on the phenotypic stability of solely the endothelial cells and on the microvessel-like structures that formed in co-culture and did not quantified or characterized the proliferation of the two cell populations independently. Krtolica et al., (Krtolica et al., 2002) proposed a methodology to quantify the proliferation of epithelial cells co-cultured with fibroblasts in which all the cells were stained with DAPI and were discriminated based on differences in fluorescence intensity. This method requires a large enough difference in nuclear staining intensity between the two cell types and in addition, the fluorescence thresholds to differentiate them have to be set manually for each image, which requires extensive subjective manual intervention (Krtolica et al., 2002).

We chose a vital labelling step to identify the two cell populations as opposed to the above methods for the following reasons. First, vitally labelling the cells before seeding is easier and more inexpensive than immunostaining provided that the vital label can be detected throughout the duration of the co-culture, which was the case in our set-up. Second, it has a wider applicability than immunostaining since it does not require specificity in the vital labels and can therefore be used, for example, in an osteoblast-fibroblast system. And finally, in this way each cell type is identified in a different fluorescence channel overcoming the limitations of Krtolica's method (Krtolica et al., 2002). Although it was not included in the present study, an immunostaining step could be combined with the present methodology to detect the expression of relevant proteins. This would allow the determination of the phenotypic stability of the two cell populations independently in the co-culture in comparison to the single cell-type controls. For example, we have tested that alkaline phosphatase expression could be detected in the osteoblast-fibroblast co-culture while retaining the original DiI and DiD labels, therefore the type and number of positive cells could be determined and compared with those of the single-cell type controls. This will be incorporated in future experiments to study the phenotypic stability of HBCs throughout the co-cultures.

Another advantage of the present methodology is that the use of CellProfiler, which allows to batch-process all the images without manual intervention, ensures a 
consistent and objective treatment of the images. The use of CellProfiler followed by analysis with Visiometrics software, that recognizes and locates each nucleus, automates the counting step in a consistent, objective and labour inexpensive way, thus ensuring that each of the cell type specific responses can be determined independently. Other automated image programs exist with similar capabilities, but some are proprietary software (as in the case of AssayBuilder, for instance) and/or require extensive knowledge of the programming language (e.g. Matlab). ImageJ, which is also freely available (Web ref. 2), might have been used instead of CellProfiler but the authors found CellProfiler more intuitive and easy to use for the current task. Visiometrics IPS is routinely used for the study of cell migration on different surfaces (Kaiser et al., 2006; Kaiser and Bruinink, 2004).

By combining these tools, the present methodology offers the following advantages:

- Image acquisition is automated

- Images are batch-processed in an consistent and objective way

- Cell counting is automated and labor-inexpensive

- Cell-type specific responses are quantifiable and therefore statistically analysable

- The choice of the investigated cell types is not restricted by the availability of cell-type specific antibodies.

By using this new methodology we were able to show that cell behaviour in co-culture was different from that in the single cell type controls. Evidence for this has also been found in other studies. For instance, reductions in total culture cell proliferation were seen by Wang et al. (Wang et al., 2007) in an osteoblast-fibroblast co-culture system in which the cells were seeded separated by a hydrogel divider that was subsequently removed allowing the cells to mix. In that study different osteoblast-fibroblast ratios (1:1, 2:1 and 2:2) were evaluated. However, their method did not allow discrimination of the population-specific contributions in the mixed section of the co-culture. In contrast, by using our methodology we could demonstrate specifically that HAFs proliferation was reduced as a result of being in co-culture with HBCs in a way correlated with the starting $\mathrm{HBC} / \mathrm{HAF}$ ratio. Although $\mathrm{HBC}$ proliferation was also reduced in some co-cultures, this was not correlated with the $\mathrm{HBC} / \mathrm{HAF}$ ratio. It is not clear why $\mathrm{HBC}$ proliferation was affected in some co-cultures and not in others. It is possible that this might have been the result of donor-to-donor variations. However, further experiments will be needed to explain this. Nevertheless, we could show that $\mathrm{HBC} / \mathrm{HAF}$ seeding ratios above approximately $6: 1$ resulted in higher $\mathrm{HBC} / \mathrm{HAF}$ ratios in the co-culture than that of the controls, whereas at a seeding ratio close to $1: 1$ the resulting $\mathrm{HBC} / \mathrm{HAF}$ ratio in the coculture at day 7 was lower than that of the controls. In other words, in terms of cell-cell competition, we saw in the co-cultures that both cell types could induce an inhibitory effect on the proliferation of the other cell type, depending on the co-culture conditions. Nevertheless, a much higher seeding HBC/HAF ratio (approx. 6:1) was needed for an overall effect to be seen in favour of the $\mathrm{HBCs}$ with respect to the controls (i.e., $\mathrm{R}_{\mathrm{CC}, 7}$ significantly higher than $\mathrm{R}_{\text {СТ, }}$ ) than needed for an overall effect in favour of the HAFs $\left(R_{C C}\right.$ significantly lower than $\left.R_{C T}\right)$. Surface structures and chemistry are known to affect cell performance. Consequently they will also influence cellcell competition/interactions. The reduction of the cell proliferation rate of one cell type is advantageous for the other cell type in the sense that it has more time to cover the available surface. Thus, only by investigating the relationships between competing cells types optimal surfaces can be defined. Since HBC-HAF interactions/ competition are relevant for the integration of permanent bone implants, future studies will focus on the investigation of these interactions using different experimental implant substrates such as titanium. Current experiments in progress involve co-culture of HBCs and HAFs on Ticovered Petri-dishes that are identical to those used in the present work, but for their surface chemistry, so that the effect of a different surface chemistry on the HBC-HAF interaction can be investigated. Furthermore, effects of surface structures on cell-cell interactions are planned.

One disadvantage of our proposed methodology is that, due to the nature of the dyes, fluorescence intensity decreases every time the cells divide so that the length of the experiments is limited by the detection of the dyes. This limitation could be solved by using stably transfected cells.

Besides quantifying cell proliferation, the present methodology also allows the characterization of the spatial distribution of the two cell types within the co-cultures by defining a segregation ratio and measuring characteristic cell-cell distances. Other authors have used clustering computation (Franssen et al., 2009) to characterize cell segregation in co-cultures. The present methodology does not count or measure the size of individual clusters within the co-cultures but combines a segregation ratio plus cellcell distances as an indirect way of determining how clustered the cell populations are without setting any subjective thresholds on what a cluster is. In this respect, we found that cell segregation varied as a function of the $\mathrm{HBC} / \mathrm{HAF}$ ratio in the co-culture, but was not correlated with the initial ratio (at 24h). This effect occurred in a cell-type dependent manner; HBCs were segregated at low ratios while HAFs were segregated at high ratios. Nevertheless both cell types were significantly segregated when the ratio was 1 to 1 . Segregation did not affect cellcell distances that in turn decreased with increasing cell densities. Time-lapse experiments will be conducted in the future to investigate if the cell segregation is the result of cell proliferation and/or migration in the co-cultures. Median HAF-HAF distances were consistently significantly lower than any of the other cell-cell median distances. We believe this behaviour to be related to the fact that fibroblasts are colony forming cells, however we have not tested if other types of fibroblasts (e.g. bone marrow fibroblasts, myofibroblasts) exhibit the same behaviour in co-culture.

In conclusion, we have developed an in vitro methodology that enables the in-depth investigation of 
heterotypic cell-cell interactions in a mixed co-culture system. The proposed method combines a simple live labelling step, semi-automated fluorescence image acquisition, automated image batch processing and a straight forward and systematic data analysis to characterize cell-cell interactions (cell population dynamics) in co-culture in terms of cell proliferation and cell spatial distribution by cell type. We believe that this methodology, which was here validated for an osteoblastfibroblast co-culture system in tissue culture plastic, resembles the in vivo environment more closely than single-cell type cultures and it may therefore be applicable to the investigation of heterotypic cell-cell interactions and potentially, for the study of the influence of biomaterial surfaces on these interactions, which is at the moment, work in progress.

\section{Acknowledgements}

We would like to thank Dr. Matthias Roesslein for his help with the statistical treatment of the data. We also thank Prof. Kuster of the Kantonsspital St. Gallen for providing the human tissue samples. EF Burguera was supported through a MICINN postdoctoral contract. M Bitar was supported by the Volkswagen Foundation (contract n\# I82297).

\section{References}

Anderson JM (2001) Biological responses to materials. Annu Rev Mater Res 31: 81-110.

Brånemark PI, Hansson $\mathrm{BO}$, Adell R, Breine U, Lindström J, Hallén O, Ohman A (1977) Osseointegrated implants in the treatment of the edentulous jaw. Experience from a 10-year period. Scand J Plast Reconstr Surg Suppl 16: $1-132$.

Carpenter AE, Jones TR, Lamprecht MR, Clarke C, Kang IH, Friman O, Guertin DA, Chang JH, Lindquist RA, Moffat J, Golland P, Sabatini DM (2006) CellProfiler: image analysis software for identifying and quantifying cell phenotypes. Genome Biol 7: R100.

Cooper LF, Masuda T, Yliheikkila PK, Felton DA (1998) Generalizations regarding the process and phenomenon of osseointegration. Part II. In vitro studies. Int J Oral Maxillofac Implants 13: 163-174.

Ferrari A, Hannouche D, Oudina K, Bourguignon M, Meunier A, Sedel L, Petite H (2001) In vivo tracking of bone marrow fibroblasts with fluorescent carbocyanine dye. J Biomed Mater Res 56: 361-367.

Franssen EHP, Roet KCD, de Bree FM, Verhaagen J (2009) Olfactory Ensheathing Glia and Schwann Cells Exhibit a Distinct Interaction Behavior With Meningeal Cells. J Neurosci Res 87: 1556-1564.

Fuchs S, Hofmann A, Kirkpatrick CJ (2007) Microvessel-like structures from outgrowth endothelial cells from human peripheral blood in 2-dimensional and 3-dimensional co-cultures with osteoblastic lineage cells. Tissue Eng 13: 2577-2588.
Gerstenfeld LC, Cruceta J, Shea CM, Sampath K, Barnes GL, Einhorn TA (2002) Chondrocytes provide morphogenic signals that selectively induce osteogenic differentiation of mesenchymal stem cells. J Bone Miner Res 17: 221-230.

Heinrich L, Freyria AM, Melin M, Tourneur Y, Maksoud R, Bernengo JC, Hartmann DJ (2007) Confocal laser scanning microscopy using dialkylcarbocyanine dyes for cell tracing in hard and soft biomaterials. J Biomed Mater Res part B 81B: 153-161.

Honig MG, Hume RI (1986) Fluorescent carbocyanine dyes allow living neurons of identified origin to be studied in long-term cultures. J Cell Biol 103: 171-187.

Honig MG, Hume RI (1989) DiI and DiO: versatile fluorescent dyes for neuronal labelling and pathway tracing. Trends Neurosci 12: 333-341.

Jiang J, Nicoll SB, Lu HH (2005) Co-culture of osteoblasts and chondrocytes modulates cellular differentiation in vitro. Biochem Biophys Res Commun 338: $762-770$.

Kaiser JP and Bruinink A (2004) Investigating cellmaterial interactions by monitoring and analysing cell migration. J Mater Sci Mater Med 15: 429-435.

Kaiser JP, Reinmann A, Bruinink A (2006) The effect of topographic characteristics on cell migration velocity. Biomaterials 27: 5230-5241.

Kirkpatrick CJ, Fuchs S, Hermanns MI, Peters K, Unger RE (2007) Cell culture models of higher complexity in tissue engineering and regenerative medicine. Biomaterials 28: 5193-5198.

Kirkpatrick CJ, Fuchs S, Peters K, Brochhausen C, Hermanns MI, Unger RE (2006) Visions for regenerative medicine: Interface between scientific fact and science fiction. Artif Organs 30: 822-827.

Krtolica A, de Solorzano CO, Lockett S, Campisi J (2002) Quantification of epithelial cells in coculture with fibroblasts by fluorescence image analysis. Cytometry 49: 73-82.

Lu HH. Wang INE (2008) Multiscale coculture models for orthopedic interface tissue engineering, in: Biomedical Nanostructures. (Gonsalves KE, Halberstadt CR, Laurencin CT, Nair LS, eds). Wiley, New York. pp 357373.

Nevo Z, Silver J, Chorev Y, Riklis I, Robinson D, Yosipovitch Z (1993) Adhesion characteristics of chondrocytes cultured separately and in cocultures with synovial fibroblasts. Cell Biol Int 17: 255-273.

Oberringer M, Meins C, Bubel M, Pohlemann T (2007) A new in vitro wound model based on the co-culture of human dermal microvascular endothelial cells and human dermal fibroblasts. Biol Cell 99: 197-207.

Oberringer M, Meins C, Bubel M, Pohlemann T (2008) In vitro wounding: effects of hypoxia and transforming growth factor beta(1) on proliferation, migration and myofibroblastic differentiation in an endothelial cellfibroblast co-culture model. J Mol Histol 39: 37-47.

Pearce AI, Richards RG, Milz S, Schneider E, Pearce SG (2007) Animal models for implant biomaterial research in bone: A review. Eur Cells Mater 13: 1-10. 
Pizzoferrato A, Ciapetti G, Stea S, Cenni E, Arciola CR, Granchi D, Savarino L (1994) Cell culture methods for testing biocompatibility. Clin Mater 15: 173-190.

Puleo DA, Nanci A (1999) Understanding and controlling the bone-implant interface. Biomaterials 20: 2311-2321.

Sanchez C, Deberg MA, Piccardi N, Msika P, Reginster JYL, Henrotin YE (2005) Subchondral bone osteoblasts induce phenotypic changes in human osteoarthritic chondrocytes. Osteoarthritis Cartilage 13: 988-997.

Spalazzi JP, Dionisio KL, Jiang J, Lu HH (2003) Osteoblast and chondrocyte interactions during coculture on scaffolds. IEEE Eng Meg Biol Mag 22: 27-34.

Spalazzi JP, Doty SB, Moffat KL, Levine WN, Lu HH (2006) Development of controlled matrix heterogeneity on a triphasic scaffold for orthopedic interface tissue engineering. Tissue Eng 12: 3497-3508.

Unger RE, Sartoris A, Peters K, Motta A, Migliaresi C, Kunkel M, Bulnheim U, Rychly J, Kirkpatrick CJ (2007)
Tissue-like self-assembly in cocultures of endothelial cells and osteoblasts and the formation of microcapillary-like structures on three-dimensional porous biomaterials. Biomaterials 28: 3965-3976.

Wang INE, Shan J, Choi R, Oh S, Kepler CK, Chen FH, Lu HH (2007) Role of osteoblast-fibroblast interactions in the formation of the ligament-to-bone interface. J Orthop Res 25: 1609-1620.

Winn SR, Mitchell J, Uludag H (2006) In vitro testing of biomaterials, in: An Introduction to Biomaterials (Guelcher SA, Hollinger, JO, eds). CRC Press, Boca Raton, FL, pp 63-66.

\section{Web references}

1. http://www.cellprofiler.org/ [25-01-2010]

2. http://rsbweb.nih.gov/ij/ [25-01-2010] 